\title{
Comunicação
}

[Communication]

\section{Ocorrência de Mannheimia haemolytica e de Pasteurella multocida em ovinos sadios e com enfermidade respiratória}

\author{
[Mannheimia haemolytica and Pasteurella multocida occurrence in healthy and affected lambs] \\ L. Viana ${ }^{1}$, R.C. Gonçalves ${ }^{2 *}$, J.P. Oliveira Filho ${ }^{1}$, A.C. Paes ${ }^{2}$, R.M. Amorim ${ }^{2}$ \\ ${ }^{1}$ Aluno de pós-graduação - FMVZ-UNESP - Botucatu, SP \\ ${ }^{2}$ Faculdade de Medicina Veterinária e Zootecnia - UNESP \\ Distrito de Rubião Junior s/n \\ 18610-000 - Botucatu, SP
}

Os ovinos são susceptíveis à infecções respiratórias, provocadas por estresse, associadas à uma grande variedade de agentes infecciosos. Dependendo do agente e das circunstâncias, podem ocorrer pneumonias virais ou bacterianas que envolvem, freqüentemente, Mannheimia haemolytica e/ou Pasteurella multocida (Martin, 1996), e ambas podem manifestar-se na forma pneumônica ou septicêmica (Davies et al., 1994). Embora M. haemolytica e P. multocida estejam associadas à pneumonia, $M$. haemolytica é a bactéria mais freqüentemente isolada (Davies et al., 1997).

No Brasil, são escassos os dados da prevalência de pneumonias em ovinos causadas por esses agentes. Na literatura consultada, encontrou-se somente relato de um surto de pneumonia causada por $P$. multocida no estado do Rio Grande do Sul (Hancock et al.,1991).

Considerando os prejuízos causados pelas doenças respiratórias em ovinos, acarretados pelas altas taxas de morbidade e mortalidade, pior conversão alimentar, retardo no crescimento e ganho de peso, condenações de carcaças e custos com medicamentos e assistência veterinária (Rusvai e Fodor, 1998), e a limitação de informações sobre a doença no Brasil, investigou-se a ocorrência de Pasteurella multocida e Mannheimia haemolytica.
Foram colhidos "swabs" nasofaríngeos e orofaríngeos em 262 ovinos, selecionados aleatoriamente em 17 fazendas de municípios da região de Botucatu-SP. O critério foi colher o material em pelo menos uma fazenda por município.

Independentemente de sexo, idade e raça, foram amostrados em cada propriedade no mínimo 10 ovinos clinicamente sadios e até cinco ovinos com afecções do aparelho respiratório. Os animais foram distribuídos em dois grupos: clinicamente sadios (sadios, $\mathrm{n}=180$ ) e portadores de afecções respiratórias (doentes, $n=82$ ), diagnosticados por exame físico, segundo critérios clínicos adotados por Stöber (1993).

As amostras, colhidas por "swabs" esterilizados e acondicionadas em tubos com $5 \mathrm{ml}$ de meio de transporte de Stuart, processadas separadamente e semeadas diretamente em ágar sangue, ágar sangue com $6 \mu \mathrm{g}$ de vancomicina (meio seletivo para os gêneros de Mannheimia e Pasteurella) e ágar McConkey, foram incubadas, em aerobiose, a $37^{\circ} \mathrm{C}$ por até 48 horas, com observação de crescimento microbiano a cada 24 horas.

As colônias selecionadas, suspeitas de pertencerem aos gêneros Mannheimia e Pasteurella, com base nas características morfológicas, foram repicadas em tubos com

Recebido em 27 de agosto de 2007

Aceito em 20 de novembro de 2007

*Autor para correspondência (corresponding author)

E-mail: calderon@fmvz.unesp.br

Apoio: FAPESP 
solução esterilizada de caldo infusão cérebrocoração (BHI) e incubadas, em aerobiose, a $37^{\circ} \mathrm{C}$, por 12 horas. Foram feitos repiques das cepas suspeitas em placas de ágar sangue de ovino a $7 \%$. As placas com os repiques foram incubadas em aerobiose, a $37^{\circ} \mathrm{C}$, por 24 horas. As colônias dessas placas serviram como inóculo para a realização dos testes de citocromooxidase, catalase e de coloração pela técnica de Gram.

As cepas citocromo-oxidase e catalase positivas foram submetidas aos testes de fermentação dos açúcares - glicose, lactose, maltose e manitol e, no caso de $M$. haemolytica, de arabnose $\mathrm{e}$ trealose -; de urease, para verificar a motilidade; de produção de indol e de redução da ornitina; e para verificar a produção e tipo de hemólise.

O meio de cultura ágar McConkey foi utilizado para verificar a capacidade de resistência de $M$. haemolytica aos sais biliares e para diferenciá-la de $P$. multocida. Todas as colônias suspeitas foram semeadas em placas de ágar McConkey, incubadas a $37^{\circ} \mathrm{C}$, em anaerobiose, e observadas após 48 horas. As cepas de $M$. haemolytica mostraram-se, após o tempo de incubação, como pequenas colônias róseas, enquanto que as espécies de $P$. multocida não cresceram nesse meio de cultura.

Usou-se o teste exato de Fisher para comparar as taxas de isolamento de $M$. haemolytica, de $P$. multocida e dessas duas bactérias associadas, na nasofaringe e na orofaringe dos dois grupos de animais, utilizando-se o programa EPI-INFO.

M. haemolytica foi a bactéria mais prevalente (47,3\%), seguida pela associação de $M$. haemolytica e de $P$. multocida (27,5\%). $P$. multocida pura apresentou a menor taxa de isolamento $(10,7 \%)$. Em $14,5 \%$ dos animais amostrados não houve crescimento desses microrganismos.

Entre os animais clinicamente sadios houve diferença nas taxas de isolamento da nasofaringe e da orofaringe (Tab. 1). Entre os ovinos do grupo doente essas diferenças não foram significativas, mas o número de animais com isolamento negativo para essas duas bactérias na nasofaringe foi maior $(\mathrm{P}<0,001)$ que na orofaringe (Tab. 2).

Tabela 1. Taxa de isolamento de Mannheimia haemolytica, de Pasteurella multocida e dessas duas bactérias associadas, na nasofaringe e orofaringe de animais sadios, na região de Botucatu, SP

\begin{tabular}{lccccc}
\hline \multirow{2}{*}{ Microrganismo } & \multicolumn{2}{c}{ Nasofaringe } & \multicolumn{2}{c}{ Orofaringe } & \multirow{2}{*}{$\mathrm{P}$} \\
\cline { 2 - 5 } & número & $\%$ & número & $\%$ & \\
\hline Mannheimia haemolytica & 61 & 33,9 & 88 & 48,9 & $0,0038^{*}$ \\
Pasteurella multocida & 6 & 3,3 & 24 & 13,3 & $0,0006^{* *}$ \\
Mannheimia haemolytica & 8 & 4,4 & 34 & 18,9 & $0,0000^{* *}$ \\
$\begin{array}{l}\text { Pasteurella multocida } \\
\text { Negativo }\end{array}$ & 105 & 58,3 & 34 & 18,9 & $0,0000^{* *}$ \\
\hline Total & 180 & 100,0 & 180 & 100,0 & \\
\hline
\end{tabular}

Tabela 2. Taxa de isolamento (\%) de Mannheimia haemolytica, de Pasteurella multocida e dessas duas bactérias associadas, na nasofaringe e orofaringe de animais portadores de afecções respiratórias, na região de Botucatu, SP

\begin{tabular}{lccccc} 
& \multicolumn{2}{c}{ Nasofaringe } & \multicolumn{2}{c}{ Orofaringe } & \multirow{2}{*}{ P } \\
\cline { 2 - 5 } & número & $\%$ & número & $\%$ & \\
\hline Mannheimia haemolytica & 29 & 35,4 & 40 & 48,8 & $0,0819 \mathrm{~ns}$ \\
Pasteurella multocida & 9 & 11,0 & 15 & 18,3 & $0,1850 \mathrm{~ns}$ \\
$\begin{array}{l}\text { Mannheimia haemolytica } \\
\text { Pasteurella multocida }\end{array}$ & 6 & 7,3 & 14 & 17,1 & $0,5620 \mathrm{~ns}$ \\
Negativo & 38 & 46,3 & 13 & 15,9 & $0,0000^{* *}$ \\
\hline Total & 82 & 100,0 & 82 & 100,0 & \\
\hline
\end{tabular}


Verificou-se maior taxa de isolamento de $P$. multocida na nasofaringe dos animais doentes $(\mathrm{P}=0,0291)$. Ainda, na nasofaringe, a taxa de isolamento de $M$. haemolytica e de sua associação com $P$. multocida não foi diferente entre animais sadios e doentes $(\mathrm{P}=0,8154$ e $\mathrm{P}=0,0706$, respectivamente). As taxas de isolamento de $M$. haemolytica, de $P$. multocida e das duas bactérias associadas na orofaringe dos ovinos sadios e doentes foram semelhantes.

Ball et al. (1993) e Sysai e Zerihun (2003) citaram dificuldades de interpretação no isolamento de $M$. haemolytica e de $P$. multocida nas amostras de "swabs" nasofaríngeos colhidos em bovinos, caprinos e ovinos, em virtude da grande quantidade de microrganismos que podem ser isolados, muitos com potencial patogênico. Tais limitações procuraram ser minimizadas no presente estudo com a utilização de meio seletivo para $M$. haemolytica e $P$. multocida, com o intuito de limitar o crescimento dos microrganismos indesejáveis, pois o objetivo deste estudo foi verificar a distribuição dos dois agentes bacterianos.

Assumiu-se, também, que cada cepa de $M$. haemolytica ou de $P$. multocida, provenientes de uma colônia, foi representativa de um animal positivo para o isolamento de um ou de outro microrganismo, de maneira similar à adotada na grande maioria dos estudos realizados para investigar a prevalência dessas duas bactérias (Ball et al., 1993; Al-Tarazi e Dagnall, 1997; Barbour et al., 1997).

Diversos autores relataram que $M$. haemolytica é a bactéria mais comumente isolada no trato respiratório de ovinos (Gilmour et al., 1991; Martin, 1996; Davies et al., 1997; Aekermann e Brogden, 2000). Na literatura brasileira consultada não foram encontradas informações sobre a incidência de $M$. haemolytica em ovinos, o que fez supor ser este estudo inédito na literatura nacional.

A maior freqüência de $M$. haemolytica, de $P$. multocida, ou dos dois microrganismos juntos na orofaringe de animais sadios é semelhante aos resultados da investigação recente, realizada na Etiópia por Sisay e Zerihun (2003). Esses autores, ao avaliarem a diversidade de espécies e sorotipos dos gêneros Pasteurella e Mannheimia, identificaram taxas de isolamento de $75,6 \%$ e $52,4 \%$ nas amostras de "swabs" da nasofaringe e da orofaringe, respectivamente. Há, contudo, relatos de isolamento de $M$. haemolytica em $100 \%$ de cavidade nasal e em $47 \%$ na orofaringe (Al-Sultan e Aitken, 1995). Nos animais sadios, o isolamento de $M$. haemolytica e $P$. multocida na orofaringe foi maior que na nasofaringe.

Narayanan et al. (2002) demonstraram que durante as doenças respiratórias ou quebra do mecanismo de defesa do hospedeiro, tanto $M$. haemolytica como $P$. multocida se multiplicam rapidamente nas criptas das tonsilas e podem disseminar-se por toda mucosa respiratória, atingindo, inclusive, o epitélio alveolar durante a inalação. Nos doentes, o número de animais com isolamento negativo para $M$. haemolytica $e P$. multocida foi maior na nasofaringe, sugerindo ser a orofaringe o melhor local para a colheita e isolamento dessas bactérias.

Em geral, na região estudada, os resultados permitem afirmar que $P$. multocida tem um papel importante na etiologia da doença respiratória. Hancock et al. (1991), ao isolarem esse microrganismo em um rebanho de ovinos no Rio Grande do Sul, alertaram para a necessidade de se investigar a participação dessa bactéria nas doenças respiratórias de ovinos no Brasil. Ao contrário, Gilmour (1978) refere-se à pasteurelose dos ovinos, como sendo causada exclusivamente por $M$. haemolytica, enquanto que $P$. multocida teria maior relevância em bovinos.

Al-Tarazi e Dagnall (1997), na Jordânia, constataram que a prevalência de $M$. haemolytica nos animais doentes era maior que nos sadios. Barbour et al. (1997) não observaram diferença significativa na prevalência de $P$. multocida entre os animais sadios e os doentes quando isolaram essas bactérias do sistema respiratório de ovinos e bovinos. Esses resultados foram, portanto, confirmados pelo presente estudo.

Palavras-chave: ovino, Mannheimia haemolytica, Pasteurella multocida, doenças respiratórias 


\begin{abstract}
Frequency of Mannheimia haemolytica and Pasteurella multocida in the respiratory tract of lambs in the region of Botucatu, SP, Brazil, was studied. Nasopharingeal and oropharingeal swabs were obtained from 262 animals: 180 from healthy and 82 from animals with respiratory diseases. M. haemolytica was the most prevalent (47\%), followed by the association of $\mathrm{M}$. haemolytica and $\mathrm{P}$. multocida (27\%), and $\mathrm{P}$. multocida (11\%). Animals with respiratory disease presented higher occurrence of $\mathrm{P}$. multocida in the nasopharynx as compared to healthy animals $(P<0.05)$. No significant difference in isolation rate of $\mathrm{M}$. haemolytica, P. multocida, and association of these microorganisms in the oropharynx of healthy and affected animals was observed.
\end{abstract}

Keywords: lamb, Mannheimia haemolytica, Pasteurella multocida, respiratory diseases

\section{REFERÊNCIAS BIBLIOGRÁFICAS}

AEKERMANN, M.R.; BROGDEN, K.A. Response of the ruminant respiratory tract to Mannheimia (Pasteurella) haemolytica. Microb. Infec., Amsterdan, v.2, p.1079-1088, 2000.

AL-SULTAN, I.I.; AITKEN, I.D. The tonsilar carriage of Pasteurella haemolytica in lambs. $J$. Comp. Pathol., v.95, p.193-201, 1985.

AL-TARAZI, Y.H.M.; DAGNALL, G.J.R. Nasal carriage of Pasteurella haemolytica serotypes by sheep and goats in Jordan. Trop. Anim. Health Prod., v.29, p.177-179, 1997.

BALL, H.J.; CANNOLLY, M.; CASSIDY, J. Pasteurella haemolytica serotypes isolated in Northern Ireland during 1989-1991. Br. Vet. J., v.149, p.561-570, 1993.

BARBOUR, E. K.; NABBUT, N.H.; HAMADEH, S.K. et al. Bacterial identity and characteristics in healthy and unhealthy respiratory tracts of sheep and calves. Vet. Res. Commun., v.21, p.421-430, 1997.

DAVIES, R.L.; PARTON, R.; COOTE, J.G. et al. Evaluation of different methods for the detection of outer membrane proteins and lipopolysaccharide of Pasteurella haemolytica by immunoblotting. J. Immunol. Methods, v.167, p.35-45, 1994.

DAVIES, R.L.; ARKINSAW, S.; SELANDER, R.K. Ivolutionary genetics of Pasteurella haemolytyca isolates revered from cattle and sheep. Inf. Immun., v.65, p.3585-3593, 1997.

GILMOUR, N.J.L.; ANGUS, K.W.; GILMOUR, J.S. Pasteurellosis. In: Diseases of sheep. 3.ed. London: Academic, 1991. p.108-111.

HANCOCK, R.D.; FALLAVENA, L.C.B.; RIBEIRO, L.A.O. Pneumonic pasteurellosis due to P. multocida in flock of lambs in Brazil. Vet. Rec., v.128, p.154-155, 1991.

MARTIN, W.B. Respiratory infections of sheep. Comp. Immunol. Microbiol. Infect. Dis., v.19, p.171-179, 1996.

NARAYANAN, S.K.; NAGARAJA, T.G.; CHENGAPPA, M.M. et al. Lenkotoxius of gram-negative bacteria. Vet. Microbiol., v.84, p.337-356, 2002.

RUSVAI, M.; FODOR, L. Occurrence of same viruses and bacteria involved in respiratory diseases of ruminants in Hungary. Acta Vet. Hung., v.46, p.405-414, 1998.

SISAY, T.; ZERIHUN, A. Diversity of Mannheimia haemolytica and Pasteurella trehalosi serotypes from apparently sheep and abattoir specimens in the highloids of wollo, North East Etiopia, Vet. Res. Commun., v.27, p.3-14, 2003.

STÖBER, M. Aparelho respiratório. In: DIRKSEN, G.; GRÜNDER, H.D.; STÖBER, M. Exame clínico dos bovinos. 3.ed. Rio de Janeiro: Guanabara Koogan, 1993. p.139-165. 